\title{
Medium-term 2DH coastal area modelling
}

\author{
H.J. de Vriend ${ }^{a}$, J. Zyserman ${ }^{\text {b }}$, J. Nicholson ${ }^{\text {c }}$, J.A. Roelvink ${ }^{a}$, P. Péchon ${ }^{\text {d }}$ and \\ H.N. Southgate \\ "Delft Hydraulics, Emmeloord, Netherlands \\ 'Danish Hydraulic Institute, Horsholm, Denmark \\ ${ }^{c}$ University of Liverpool, Liverpool, $U K$ \\ 'EDF - Lab. National d'Hydraulique, Chatou, France \\ 'HR Wallingford, Wallingford, UK
}

(Received 1 October 1992; accepted after revision 1 June 1993)

\begin{abstract}
The state-of-the-art in depth-averaged mathematical modelling of 3-D coastal morphology is described for the medium-term morphodynamic model type, in which constituent models of waves, currents and sediment transport based on first physical principles are linked together to describe the time-evolution of the bed topography. Various aspects of the combined system of equations are discussed, such as its mathematical character, its inherent stability and its equilibrium state. The results of an intercomparison of different models are shown for two test cases and the potentials and limitations of the model concept are discussed.
\end{abstract}

\section{INTRODUCTION}

Coastal evolution processes are often three-dimensional. Yet, important aspects of the coastal behaviour can be understood and predicted with modelling concepts based on fewer dimensions, because the coastal system often behaves at different length and time scales in the vertical, cross-shore and longshore directions.

This has led to a range of practically useful numerical model concepts, such as

- coastline models, which describe only the largest-scale behaviour (longshore) after having integrated over the smaller scales (vertical, crossshore),

- coastal profile models, which ignore the longshore variation, but include the vertical dimension and concentrate on the medium-scale cross-shore evolution,

- coastal area models, based on depth-averaged current modules, in which both horizontal dimensions are taken into account, or 
- local models, which ignore the larger and intermediate horizontal scales and concentrate on small-scale phenomena (e.g. ripple formation) in which the vertical dimension cannot be ignored or parameterized.

Besides, numerous intermediate model types have been developed (e.g. multi-line models, multi-profile models ).

The present paper concerns models for situations in which the horizontal dimensions cannot be separated according to the scales of the morphological processes. Common examples of such situations are the morphological evolutions near structures, river outflows, tidal inlets, etc. The system can be more complex than one might expect at first sight, for instance due to the presence of rip channel and bar systems.

After an outline of the basic concepts of various models which are claimed to describe 3-D coastal evolution, we will discuss two model types: initial sedimentation and erosion models, and medium-term morphodynamic models. We will then consider various theoretical aspects of the latter, and show some results of numerical model experiments. Finally, we will consider the need for a 3D or quasi-3D current module in order to describe the evolution of the beach and the foreshore.

\section{BASIC MODEL CONCEPTS}

At both the conceptual level and the numerical implementation level, multidimensional coastal evolution models usually start from a number of more or less standard models of the constituent physical processes (waves, currents, sediment transport), which are coupled via a bottom evolution module based on sediment conservation. Fig. 1 summarizes the basic model concepts.

The figure represents three basic concepts, viz.

(1) "initial sedimentation/erosion" (ISE) models, which go only once through the sequence of constituent models; in fact, the hydrodynamic and sediment transport computation is based on the assumption of an invariant bed topography and only the rate of sedimentation or erosion for that topography is computed at every location,

(2) "medium-term morphodynamic" (MTM) models, in which the new bottom topography is fed back into the hydrodynamic and sediment transport computations; this yields a looped system which describes the dynamic time-evolution of the bed. The timescale of this essentially deterministic "morphodynamic" simulation (Wright and Thom, 1977; see also De Vriend, 1991b) cannot be substantially larger than the hydrodynamic time scale (duration of a storm, tidal period), even allowing for future improvements to the efficiency of time-stepping techniques,

(3) "long-term morphological" (LTM) models, in which the constituent equations are not describing the individual physical processes, but integrated processes at a higher level of aggregation. 


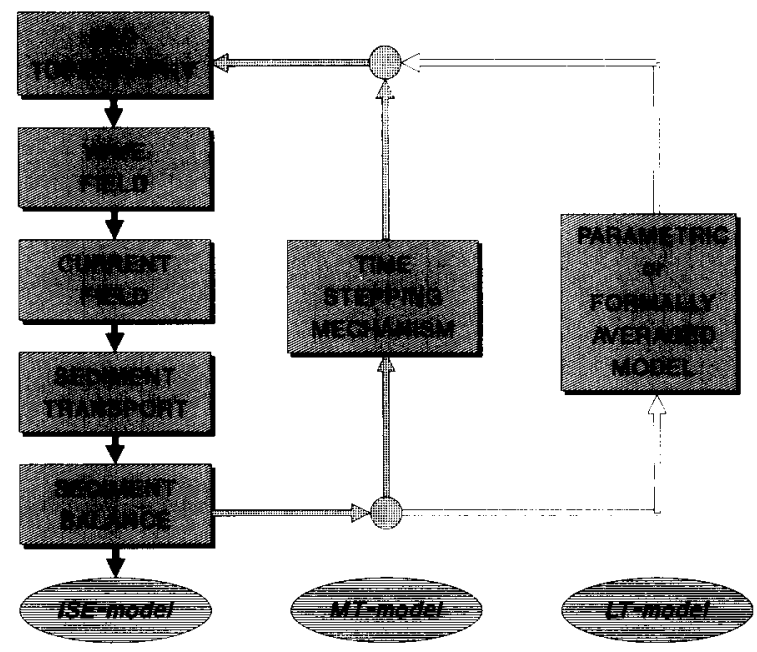

Fig. 1. Compound morphological model concepts.

In the next sections, we will briefly address ISE-models and concentrate further on MTM-models.

\section{ISE MODELS: POTENTIALS AND LIMITATIONS}

The series of constituent process models which forms an ISE-model is an essential element in all morphological modelling approaches. The composition of this series is far from trivial and determines to a high extent the quality of the final result (cf. De Vriend, 1987a).

We will not discuss the "minefield" of morphological model composition at length here, but concentrate on a few aspects.

The part of the compound model system which is used for initial sedimentation/ erosion models is indicated in Fig. 1. As one might expect, models of the ISE-type are the widest used in practice. The computational effort involved is relatively small and the implementation is relatively easy. Moreover, the latest process descriptions can usually be included without too many unexpected complications (although there is still a risk of spurious interactions or an unexpected role of small terms; for instance, see Dingemans at al., 1987, or De Vriend and Ribberink, 1988).

Models of this type, however, are difficult to interpret in terms of longerterm morphological evolution, and they can only strictly provide information on phenomena at a time scale much smaller than the morphological one.

Given these potentials and limitations, the question is how to make optimum use of ISE-type models. Obviously, they describe the constituent processes and their instant interactions, and they provide possibilities to experi- 


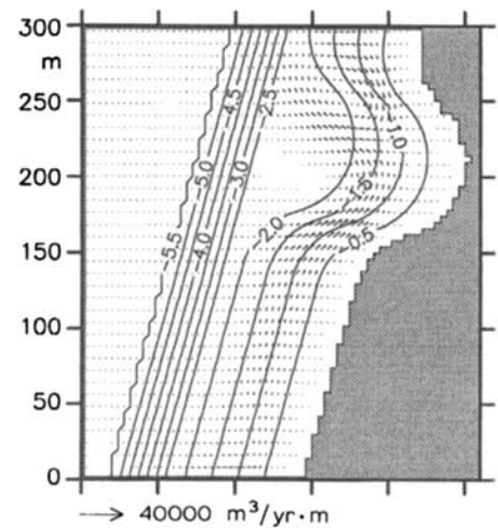

(a)



$\mathrm{dz} / \mathrm{dt}$ (m/day) (c)

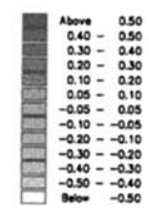

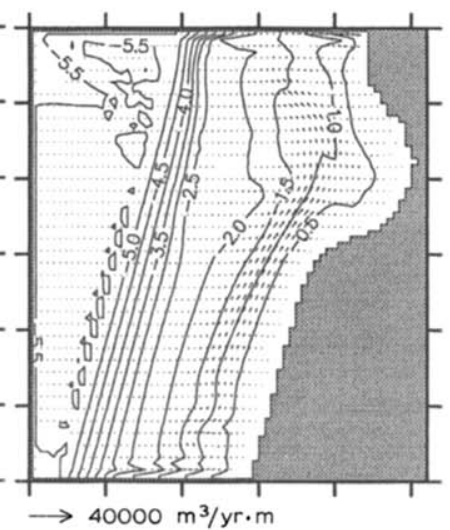

(b)

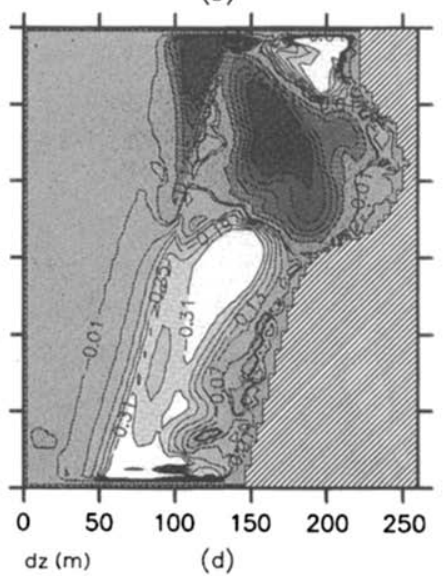

(d)

Fig. 2. Representativeness of ISE model results for medium-term morphological evolutions: (a) initial bathymetry and transport pattern, (b) bathymetry and transport pattern after 5 days, (c) initial rate of bed level change, (d) rate of bed level change after 5 days.

ment with real-life input conditions. On the other hand, they are unable to represent the dynamic behaviour of the system, let alone predict the equilibrium state.

The principal results of an ISE model are the sediment transport field and the sedimentation/erosion pattern. Experiments with 3D medium-term morphodynamic models show that the initial sedimentation/erosion rate is not always very representative of what happens after some time, whereas the 


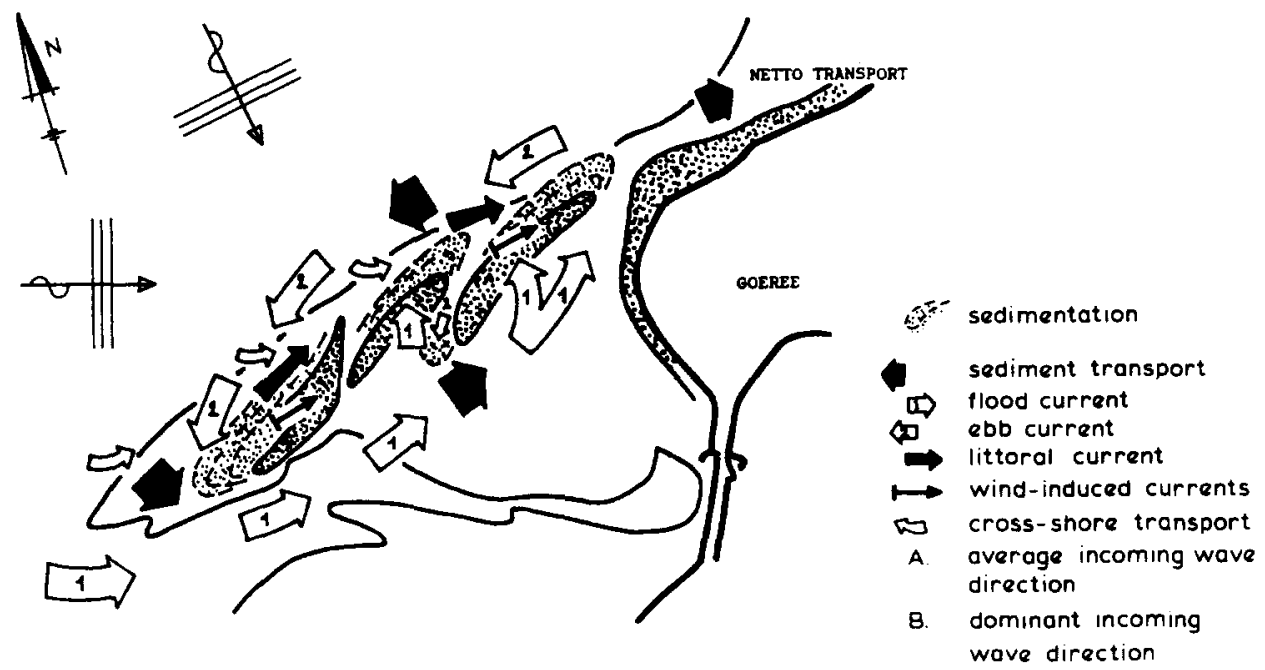

Fig. 3. Overall process analysis based on an ISE-model (from Steijn et al., 1989; courtesy Gower Technical, Aldershot ).

transport pattern is usually more so (see the example in Fig. 2). Also the interpretation of ISE model results in terms of longer-term morphological prediction is often easier on the basis of the estimated yearly residual transport field.

ISE-models can be used in comparative studies, e.g. to predict the effects of different designs of a coastal structure (cf. Walker et al., 1991). The response to such interference with the natural system is usually governed by only a few processes, and the ISE-model is a good tool to identify them and to assess the structure's impact on them.

Another way to utilize ISE-models is to test the contributions of various individual sets of conditions (storms, moderate wind periods from various directions, calm weather periods, spring tide, neap tide ) to the residual transport and sedimentation/erosion fields. In complex situations, such as tidal inlets, the answer is not obvious, especially as proposed engineering works tend to have different effects under different conditions. Examples of such studies are described in Steijn et al. (1989) and Steijn and Louters (1992).

ISE-models can also be used for the analysis of overall transport processes in complex situations, before and after changes or measures. Once the model has been validated and has shown its reliability, it can be used to unravel the physical processes at a global level (in contrast to the constituting differential equations, which describe the processes at a local level). Fig. 3 shows an example of such an analysis.

The use of ISE-models is not necessarily restricted to sand transport: they can also be used to describe the transport and the fate of cohesive sediment (for instance, see Fritsch et al., 1989; Villaret and Latteux, 1992). 
In contrast to ISE-models, MTM-models (see Fig. 1) describe the dynamic behaviour of the morphological system. Although some interesting applications have been shown (Latteux, 1980; Yamaguchi and Nishioka, 1984; Chaloin et al., 1985; Watanabe et al., 1986; Maruyama and Takagi, 1988; Shimizu et al., 1990; Andersen et al., 1988, 1991; Watanabe et al., 1991 ), these models are still in a rather early stage of development. Important problems remain to be solved, at the conceptual as well as the implementation level. Some of these will be discussed later in this section.

Once these problems have been solved, and with future reductions in computational expense, MTM-models can be a powerful tool for morphodynamic simulations up to time spans of the relevant morphological evolution, provided that physical understanding keeps up with the potential of the numerical models.

MTM-models are not likely to be able to cover time spans which are much larger than the inherent time scale of the relevant morphological evolution. The described process is non-linear, and the input conditions are uncertain and include extreme events, so the predictability of the morphological evolution must be expected to decrease as the time span increases. Further quantification of this statement, however, is still a research issue.

2DH MTM-MODELS: THEORETICAL ASPECTS

General

2DH morphodynamic models are being developed all over the world, also in Europe (Latteux, 1980; Coëffé and Péchon, 1982; De Vriend, 1987a; Gallerano and Rufini, 1989; O'Connor and Nicholson, 1992; Andersen et al., 1988,1991 ). Their composition is usually as follows:

- a wave field model;

- a wave-driven force computation on the basis of radiation stresses or wave energy dissipation,

- a depth-integrated current model which describes the depth-averaged velocity field without vertical resolution; all information on the vertical flow structure is lumped into the closure hypothesis for the bottom shear stress, which assumes plane shear flow including wave effects; external forces cannot be distinguished by the level at which they act;

- a sediment transport formula or a depth-integrated suspended load model which describes the depth-averaged sediment concentration without vertical resolution; 
- a sediment balance module which computes the bed level changes from the divergence of the transport field.

Combining these components, however well-understood on their own, yields a new dynamic system whose behaviour is still poorly understood. Using mathematical techniques, we can investigate the behaviour of that system without solving all the equations. This reveals the flow of information through the model domain and the inherent stability of the system (i.e. whether the exact solution of the differential equations is stable).

\section{Flow of information and boundary conditions}

The combination of process models constitutes a new system, which has to be analysed before being implemented in a numerical model. For instance, we have to assess whether the mathematical system is well-posed. To that end, we have to know the mathematical character of the system (e.g. hyperbolic, parabolic, elliptic), and therefore how information flows through the model domain. This tells us where we have to impose boundary conditions and on which variables. Furthermore, this information can be of use when setting up the numerical scheme.

Without going into the details of the characteristics analysis (see De Vriend, $1987 \mathrm{~b}$ ), we can state that the present MTM-models are of a mixed character, but that the bottom evolution is to a large extent hyperbolic. The information propagates along with the sediment transport, but on top of that it spreads out at a finite speed, due to the interaction with the current field. A further analysis reveals that one morphological (or transport) boundary condition is required at every boundary where sediment enters the domain. (Note that in tide-averaged models this is not always the boundary where the residual current comes in!)

The predominant hyperbolic character of the morphological evolution implies that the numerical scheme should be suited to advect information in all directions. This means, that stability and/or accuracy are governed by a CFLcriterion based on the maximum celerity of small bottom perturbations, which is slightly higher than in the 1D-case (De Vriend, 1987b).

\section{Inherent stability}

A first impression of the inherent stability (i.e. the stability at the level of the differential equations, as opposed to that of the discretized equations) can be obtained from a "normal mode analysis" of the linearized equations (for instance, see De Vriend, 1988). This entails perturbing a basic state of the system (e.g. a trivial solution) with Fourier modes and investigating which of these modes tend to grow and which one grows fastest.

One of the problems with multi-dimensional morphodynamic models which 
emerges from this type of analysis concerns the slope-related transport mechanism, which is usually rather weak, but of major importance to the inherent stability of the system. In fact, the downslope gravitational transport is the most important mechanism to keep short-wave perturbations of the bed from growing exponentially, and slope-related transport mechanisms enable the coastal profile to reach a dynamic equilibrium state.

Instability of the basic state of the bed to certain Fourier-mode perturbations is an inherent property of the system of differential equations. Therefore, it cannot be removed by improving the numerical implementation. Conversely, if the numerical implementation of this model gives a stable solution, this is likely to be due to numerical smoothing effects, which are often present in models of this complexity.

The only physically sound remedy for instability of all modes is to include the slope-limiting effects which are present in nature. The most effective one is the downslope gravitational transport component, which can be included as follows (see also Horikawa, 1988)

$q_{x}=q_{x}^{1}-\beta\left|q_{\mathrm{t}}^{1}\right| \frac{\partial z_{\mathrm{b}}}{\partial x}$ and $q_{y}=q_{y}^{1}-\beta\left|q_{\mathrm{t}}^{1}\right| \frac{\partial z_{\mathrm{b}}}{\partial y}$

in which $x$ and $y$ are horizontal cartesian coordinates, $q_{x}$ and $q_{y}$ are the transport components, $q_{x}^{1}$ and $q_{y}^{1}$ are their equivalents for a horizontal bed, $\left|q_{\mathrm{t}}^{1}\right|$ is the total transport rate for a horizontal bed, $z_{\mathrm{b}}$ is the bed level and is $\beta$ a constant coefficient.

Some authors propose different versions of Eq. (1), e.g. with different coefficients for the downstream and the cross-stream components (Struiksma et al., 1985; Watanabe et al., 1986). There are arguments for this anisotropy, but further research is needed.

The effect of this additional transport component is that suppression of modes takes place, especially in the higher wave number ranges. In physical terms, the effect is diffusive, as becomes evident when taking the divergence of the transport rates according to Eq. (1).

However, not all modes are damped: a restricted class, with the crest under an acute angle with the transport direction, remains growing (De Vriend, 1986). This concerns very large and slowly growing features which occur in nature (for example, linear sand banks; see Huthnance, 1982; also see Pattiaratchi and Collins, 1987).

The actual hydrodynamic modules used in coastal morphodynamic models are more complicated than those in the above analysis. They include other stabilizing elements, such as horizontal diffusion of momentum, or shortcrested waves. This may explain why the test runs presented hereafter yield stable results, even though the numerical scheme is claimed to be free from numerical diffusion. A rigorous stability analysis for these models remains to be made. 
Coastal morphodynamic models contain a multitude of non-linear elements (e.g. advection, bottom friction, transport model), which may lead to non-linear instability. Consequently, the model may suddenly start producing nonsensical results or become unstable after a seemingly stable and sound computation over a long period of time.

\section{Equilibrium bed topography}

The problems concerning the equilibrium bed topography have to a large extent the same cause as those of the inherent stability, viz. the inadequate modelling of slope-related transport mechanisms. If these effects are ignored, the model can be inherently unstable, but it can also yield an unrealistic equilibrium state.

A simple illustration of this statement is given in Fig. 4, for a beach which is uniform in the longshore direction and which is exposed to a stationary obliquely incident wave field.

If this situation is modelled without the downslope gravitational transport, the mechanisms which connect the various depth zones are very weak (horizontal diffusion of momentum), or physically unrealistic (numerical diffusion ). Each depth zone in such a model, however narrow, is therefore virtually independent of its neighbours. Hence the beach profile can take any shape, as long as it complies with the upstream boundary condition (Fig. 4a).

This is in contrast to various observations, in laboratory experiments and in nature, e.g.

- the shape of especially the upper part of the cross-shore profile of a nearlyuniform coast evolves much faster than the longshore topography (Péchon, 1988; Howd and Birkemeier, 1987);

- the beach profile tends towards an equilibrium shape which is a function of the hydrodynamic conditions and the sediment properties, but not of the longshore topography (Dean, 1977; also see Horikawa, 1988).

Both observations indicate that the profile evolution process is not primarily dependent on the longshore topography.

In mathematical terms, the bed evolution has too much of a propagation

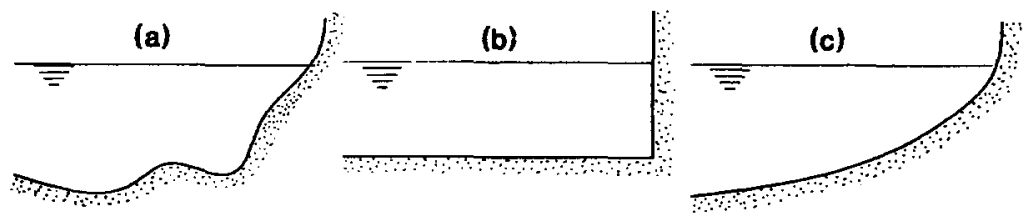

Fig. 4. Longshore uniform equilibrium beach: (a) without cross-shore transport mechanisms, (b) cross-shore slope-induced transport included (and dune front fixed), (c) natural long-term average beach profile. 
character and too little of a diffusion character, as is illustrated by reworking the mass conservation equations for the water and the sediment into (for instance, see De Vriend, 1988)

$$
\begin{aligned}
\left(1-\epsilon_{\mathrm{p}}\right) \frac{\partial z_{\mathrm{b}}}{\partial t}+\frac{\left|q_{\mathrm{t}}^{1}\right|}{h}\left(b_{1} \frac{\partial z_{\mathrm{b}}}{\partial s}+b_{2} \frac{h}{R_{\mathrm{n}}}\right)-\beta\left[\frac{1}{l_{\mathrm{n}}} \frac{\partial}{\partial s}\left(\left|q_{\mathrm{t}}^{1}\right| l_{\mathrm{n}} \frac{\partial z_{\mathrm{b}}}{\partial s}\right)\right. \\
\left.+\frac{1}{l_{\mathrm{s}}} \frac{\partial}{\partial n}\left(\left|q_{\mathrm{t}}^{1}\right| l_{\mathrm{s}} \frac{\partial z_{\mathrm{b}}}{\partial n}\right)\right]=0
\end{aligned}
$$

in which $t$ is time, $s$ is the distance along the streamline, $n$ is the distance along the normal line, $R_{\mathrm{n}}$ is the radius of curvature of the normal line, $l_{\mathrm{s}}$ and $l_{\mathrm{n}}$ are the metric coefficients of the curvilinear natural coordinate system (for instance, see Rouse, 1965), $\epsilon_{\mathrm{p}}$ is the porosity of the bed, $h$ is the water depth, and $b_{1}$ and $b_{2}$ are constants.

Although Eq. (2) does not describe all of the bed behaviour, it does show the effect of ignoring the downslope gravitational transport $(\beta=0)$ : only the propagation terms and the source term with $R_{\mathrm{n}}$ remain. As the source term only represents the effect of convergence and divergence of the streamlines, this implies that the equilibrium bed topography depends strongly on the upstream boundary condition, irrespective of how far the boundary is away.

This does not formally prove the deficiency of models which ignore the cross-stream gravitational transport, but it strongly suggests that this effect ought to be included, especially in nearshore applications.

Including the downslope gravitational transport may still be not enough for the equilibrium bed topography to make sense. In the case of the longshore uniform beach, for instance, the bed will become horizontal if the beach or the dune front do not act as a source of sediment (Fig. 4b). This is readily shown by omitting the s- and t-derivatives and the $R_{\mathrm{n}}$-term from Eq. (2).

The diagnosis is simple: for the model to yield sensible results in the longer run, it is necessary to include all important slope-affecting mechanisms. As far as cross-shore profile evolution is concerned, a significant part of these effects is related to the vertical flow structure (e.g. undertow and mass flux ). As a consequence the strictly $2 \mathrm{DH}$ model concept is not suited for mediumterm coastal morphodynamic simulations in which the cross-shore profile evolution plays an important role. Such cases require a description of the 3D flow structure.

In situations where the cross-shore profile evolution can be separated from the 3D evolution of the foreshore, for instance because it takes place at a much smaller time scale, it may be possible to include the profile behaviour in a parametric way into a 2DH model (cf. Ohnaka and Watanabe, 1990). This will often be the case for beaches on nearly-uniform coasts.

Finally, slope-related effects are not always and everywhere important. In the rather common case of scour near the tip of a groyne, for instance, flow 
contraction is the main mechanism (cf. Gallerano and Rufini, 1989). The $2 \mathrm{DH}$ approach is probably suitable for morphological predictions in such cases, which makes $2 \mathrm{DH}$ models worth investigating. Besides, the experience which is built up here will be of use to further developments in (quasi-) 3D modelling.

In cases where cross-shore profile evolution is not very important and the general flow pattern does not change too much during the bed evolution, it may be worthwhile to attempt a direct computation of the equilibrium bed topography. The key element in such a computation is the steady-state version of the sediment balance equation,

$\frac{\partial S_{x}}{\partial x}+\frac{\partial S_{y}}{\partial y}=0$

in which we can write the transport components $S_{x}$ and $S_{y}$ in terms of the magnitude $S$ and the direction $\phi$ of the transport vector:

$S_{x}=S \cos \phi$ and $S_{y}=S \sin \phi$

If we transform Eq. (3) to a natural coordinate system which follows the streamlines and the normal lines of the current field (and hence the transport field), we find

$\frac{\partial S}{\partial s}=-S\left(\frac{\partial \cos \phi}{\partial x}+\frac{\partial \sin \phi}{\partial y}\right)$

in which $s$ is the distance along the streamlines. If the transport direction is known, the transport rate in the equilibrium state can be determined by integrating Eq. (5) along the streamlines, starting from the sediment inflow boundaries.

The next steps are to express the actual transport rate in terms of the water depth and to invert this relationship. If we assume the flow rate to be invariant, a power-law transport formula can be written as

$S=a h^{b}$

in which $S$ is the actual (non-equilibrium) transport and $a$ and $b$ are constants which are still unknown.

We can determine these constants in every point of the computational grid from two transport computations, one based on a complete hydrodynamic computation on the actual bed topography, and another for a slightly shifted bed and a velocity adjustment based on flux invariance. Once these constants are known, we can compute the equilibrium water depth by inversion of Eq. (6)

$h_{\mathrm{eq}}=\left(\frac{S_{\mathrm{eq}}}{a}\right)^{1 / b}$ 
Clearly, this approach has severe limitations, such as a restriction to cases where the initial transport field gives a reasonable estimate of the ultimate one. We will show an example of such a case at the end of the next chapter.

\section{DH MTM-MODELS: NUMERICAL MODEL EXPERIMENTS}

\section{General}

Even an MTM-model which consists of well-established and extensively tested constituent models cannot guarantee a good result for the model as a whole. The combination of modules forms a new system, with its own behaviour, peculiarities and pitfalls. In the foregoing we have discussed this behaviour from a theoretical and rather qualitative point of view. This is not enough for the development of a numerical model; the numerical solution procedure has to be considered and the model has also to be tested quantitatively.

Two-dimensional analytical solutions of a complex mathematical system like this are scarce. Furthermore, laboratory and field experiments usually include beach profile evolution and, sometimes, dune erosion. This excludes them as test cases for a $2 \mathrm{DH}$ model.

An intercomparison of models is an alternative for early testing: it enables us to eliminate major flaws, and to assess the sensitivity to model composition, numerical schemes, time-stepping procedures, etc. Therefore, the MAST G6M project (De Vriend, 1991a) included a joint test programme for four different MTM-models which are being developed at various European institutes. It was not the idea to assess which model is the best, but rather to find the principal points of sensitivity at the conceptual level.

In the following, two hypothetical test cases will be discussed in detail.

\section{Model composition}

The four models which were used in the intercomparison tests are being developed at the Danish Hydraulic Institute (DHI), Delft Hydraulics (DH), the University of Liverpool (UL) and HR Wallingford (HR), respectively. Table 1 gives a summary of their compositions.

\section{(a) The DHI-model}

The wave module in the DHI-model is based on the HISWA concept (Holthuijsen et al., 1989), which describes the propagation, growth and decay of short-period short-crested stationary wind-wave fields. The formulation accounts for the effects of refraction and shoaling, generation by wind, dissipation by bottom friction and breaking, and refraction and blocking of the waves due to the action of currents. 
TABLE 1

Coastal area model concepts in MAST-G6M

\begin{tabular}{lllll}
\hline Module & DHI & DH & UL & HR \\
\hline Waves & PDR & PDR/MSS & KET/WCI & MSS/WCI \\
Current & 2DH & 2DH & 2DH & 2DH \\
Transport & ID/EQ/W & EQ & EQ & EQ \\
Topography & LWE/UD & ISE/UD & LWE/EBP & LWE/UD \\
\hline
\end{tabular}

MSS: mild-slope, stationary; PDR: param. spectral refr., incl. dir. spreading; WCI: incl. wave-current int.; KET: kinem., energy, time-dep.; EQ: equilibrium transport; W: wave-borne transport; ID: intrawave, diffusion; 1SE: 1-step explicit; LWE: Lax-Wendroff explicit; UD: wave and current update; EBP: emp. beach profile.

The flow module determines the the water levels and fluxes due to a variety of forcing functions (e.g. wind, barometric pressure gradients, radiation stresses) by solving the shallow water equations. A detailed description can be found in Abbott et al. (1981) and Abbott and Larsen (1985).

The morphological unit of the system describes the sediment transport and the bed level changes due to the combined action of waves and currents. The sediment transport model is based on DHI's intra-wave STP-model (Deigaard et al., 1986a,b), which describes non-cohesive sediment transport due to coexisting waves and currents under arbitrary angles, for breaking as well as non-breaking waves. The effects of wave asymmetry, small-scale bed forms (wave ripples) and graded sediments are taken into account. A modified LaxWendroff scheme is used for the bathymetry update (see Andersen et al., 1988 ), in order to have a second-order scheme without numerical diffusion. A predictor/corrector method is used to advance the solution in time, with a CFL-type criterion for the time step (see Andersen et al., 1991).

\section{(b) The DH-model}

HISWA (see above) is used as a wave module in the DH-model. Apart from wave heights and directions, the wave module produces wave-induced forces according to the dissipation-formulation, instead of the radiation stresses (see Dingemans et al., 1987).

The flow module, which solves the shallow water equations on an orthogonal curvilinear grid, allows for a variety of forcing mechanisms, including wave-induced forcing (see Stelling and Leenderste, 1992). It also includes the effects of waves on mass fluxes and bottom shear stresses. Special measures are taken to assure that the boundary conditions in the surf zones (flow velocities or water levels) are consistent with the model formulation inside the domain. The sediment transport module gives access to a choice of transport 
formulae and wave-averaged advection/diffusion models for suspended load transport. In the present test cases, the Bijker formula was used.

A Lax-Wendroff-type 1-step explicit numerical scheme (with a built-in timestep optimization) is used for the bathymetric update. In order to avoid too many runs of the relatively expensive wave and current modules, the interval between those runs is extended by using a highly simplified intermediate update technique for the flow velocity and the wave orbital velocity, assuming invariance of mass fluxes and wave-energy fluxes.

\section{(c) The UL-model}

The wave module of the UL-model is based on the kinematic conservation equation, with diffraction, and the energy conservation equation. It describes long-crested waves with a Rayleigh height distribution and includes the effects of wave-current interaction and wave breaking (energetics-based).

The current module solves the shallow water equations and includes waveinduced forcing via radiation stress gradients. Both the wave and current modules are described in Yoo and O'Connor (1986).

The sediment transport module comprises an empirical transport equation, which is based on available laboratory and field data.

The module which handles the topographical changes solves the mass balance equation for the sediment using a modified Lax-Wendroff scheme. In contrast to the other models, it incorporates slope effects similar to Eq. (1). Like in the DH-model, the time-stepping mechanism consists of two nested loops, with a complete hydrodynamic update in the outer loop and a highly simplified update in the inner loop. The length of each inner-loop time step is controlled by a CFL-criterion, while the number of inner loops constituting an outer loop is controlled by a limiting depth change condition.

\section{(d) The HR-model}

The wave module uses a forward marching solution of the time-independent Mild-Slope Equation, expressed in the form of transport and eiconal equations, the latter including diffraction terms. It accounts for wave refraction and shoaling, diffraction and dissipation by bottom friction and breaking. Driving forces for current generation are calculated directly from the dissipation formulation. The wave module is described in Southgate and Goldberg (1989).

The current module solves the shallow water equations. Currents are driven from the boundaries and via internal (e.g. wave-generated) forces. The boundary conditions (water levels or flow velocities) include the effects of wave-induced set-up and longshore driving forces. A description is given in Miles and Cooper (1985).

Two alternative sediment transport models are available. One uses a simple 
power law for the effects of currents with wave stirring and a threshold-ofmotion criterion (see Chesher and Miles, 1992). The other uses an energetics approach incorporating currents plus wave stirring, wave asymmetry effects, wave mass transport and gravity (Bailard, 1981; Stive, 1986). In the tests presented herein, the power law option was chosen.

The topographical update module solves the sediment balance equation using a Lax-Wendroff scheme, with a CFL-type stability condition. A convergence test in the flow module is used to reduce the effort in the hydrodynamic computations.

\section{Case 1: semi-circular bay}

The first test case concerns a semi-circular bay in an otherwise straight coast, which lies in a closed basin with its sidewalls parallel to the direction of wave incidence, at an angle of $15^{\circ}$ to the undisturbed coastline (Fig. 5a). One of the reasons for selecting this case was its resemblance to a series of mobilebed model tests at EDF-LNH (Péchon, 1985; see also Péchon, 1988).

The numerical simulation of the experimental case, with its light-weight sediment ( $500 \mu \mathrm{m}$ bakelite, density 1.4 ) and its unnaturally steep slopes (1:17) due to the vertical distortion, can be expected to cause problems for various model components (e.g. mild-slope wave models and sediment transport models).

Therefore, the case is scaled up to a more natural situation by multiplying the horizontal dimensions by 20 and the vertical ones by 10 , without further concern for scale effects. The sediment is assumed to be uniform sand of 200 $\mu \mathrm{m}$ median grain size and a fall velocity of $0.022 \mathrm{~m} / \mathrm{s}$. In the numerical simulation, the semi-circular bay has a radius of $50 \mathrm{~m}$. The beach has a slope of $3 \%$, which is connected in the bay by a horizontal plane at $2.3 \mathrm{~m}$ below the mean water level. Between the (straight) depth contours of $2.3 \mathrm{~m}$ and $5.5 \mathrm{~m}$ there is a 9\% slope. From the toe of this slope to the "wavemaker" boundary, some $20 \mathrm{~m}$ away, the bed is plane. All models use a uniform rectangular grid of 66 nodes cross-shore ( $x$-direction) and 76 nodes longshore ( $y$-direction), with a grid size of $4 \mathrm{~m}$ in either direction.

The model is driven by irregular long-crested waves with their crests parallel to the "wavemaker" boundary, and with a root-mean-square wave height of $0.6 \mathrm{~m}$ at that boundary. The peak period is $5 \mathrm{~s}$. The wavemaker boundary and the lateral boundaries are closed for the mean water motion and the sediment transport.

A constant Manning number of $0.03125 \mathrm{~m}^{1 / 3} / \mathrm{s}$ is used to describe the bed resistance in the flow module. The eddy viscosity in the horizontal diffusion terms is taken $0.05 \mathrm{~m}^{2} / \mathrm{s}$ throughout the area.

This case was run with each of the four models. Fig. 5 shows some of the results for the initial bathymetry. The wave models yield quite similar results for this rather simple case. The inclusion of wave-current interaction in the 

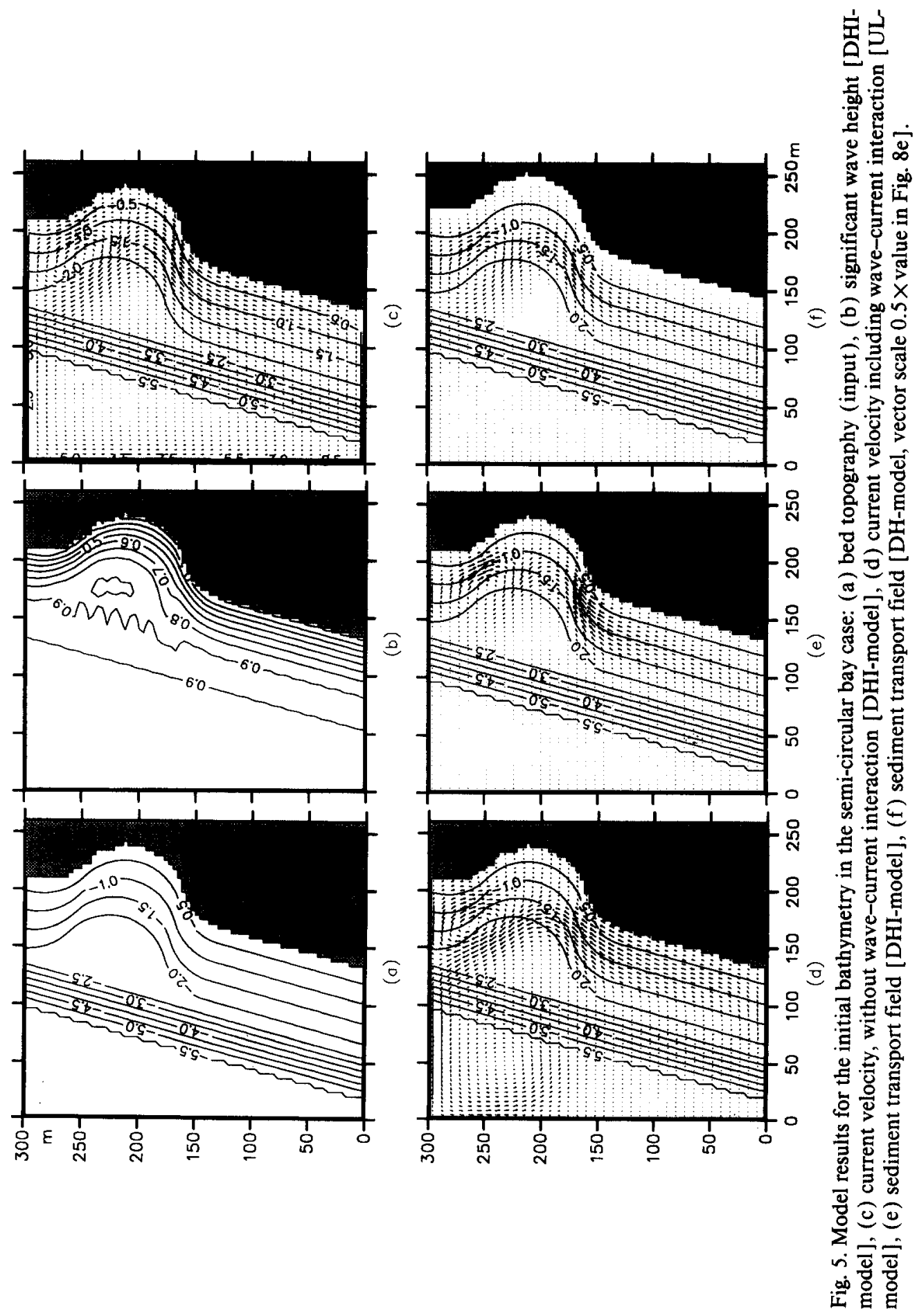



Fig. 6. Model results for the semi-circular bay case after 1.5 days of morphological evolution: sediment transport (left) and cumulative bed level change (right), according to the DHI, DH, HR and UL models, respectively. 


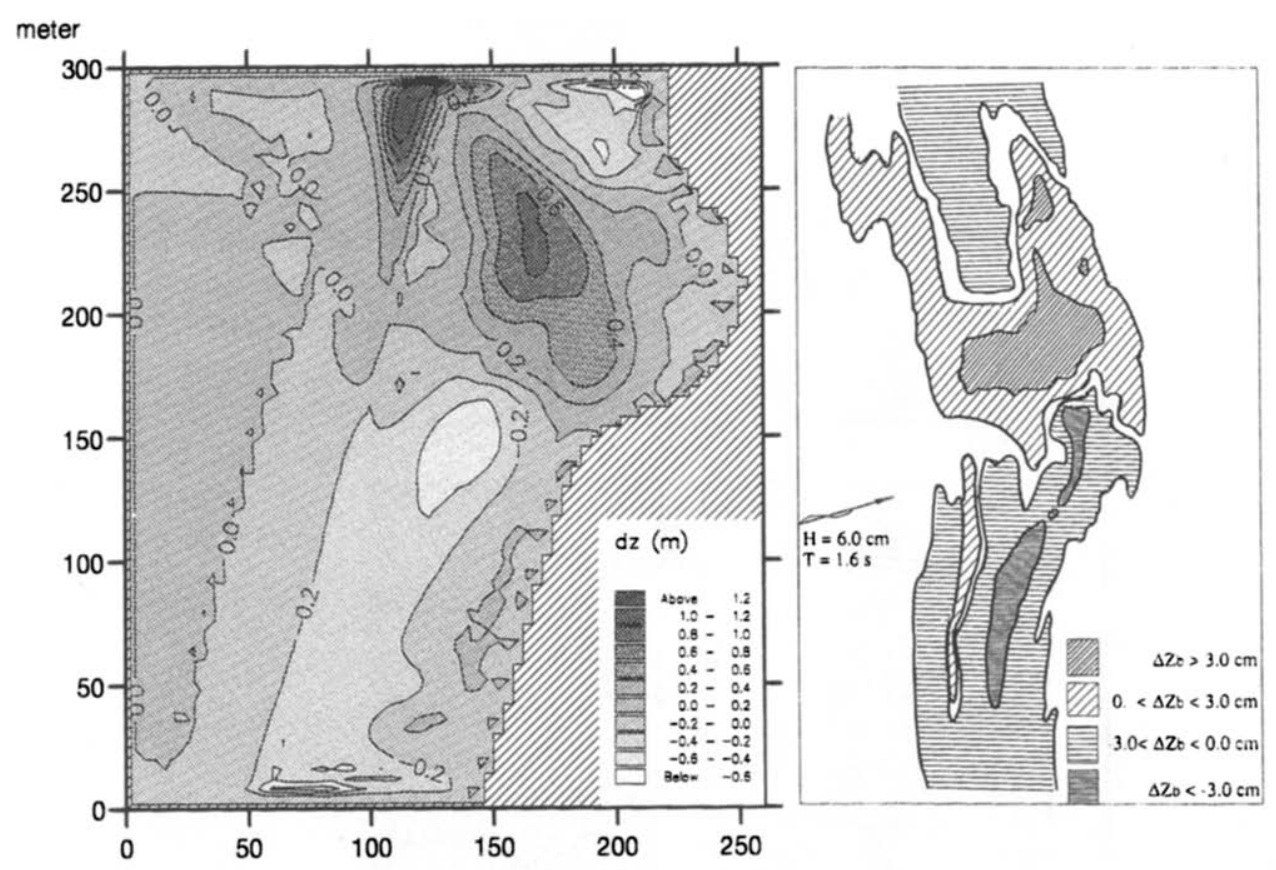

Fig. 7. Comparison of model results (left) and experimental data (right) for the semi-circular bay case.

UL-model appears to have a minor effect which is concentrated near the downdrift end of the bay (in terms of the undisturbed straight coast) and in the top left corner of the basin. The most important morphological agent, viz. the flow through the bay, is quite similar for all models.

Although the transport patterns are rather similar, the rates of transport differ significantly, the transports predicted by the DHI- and DH-models being significantly larger than those resulting from the UL-model, which in turn are significantly larger than those from the HR-model. Upon closer inspection, the transport through the bay in the DHI-model is weaker relative to the nearshore transport from either end into the bay. Due to lack of measured data, we are unable to decide which prediction is the best.

In spite of the differences in the sediment transport, the patterns of morphological changes after 1.5 days of evolution are rather similar (Fig. 6). All models predict a deposition in the bay, at the expense of the adjacent coast. The differences between the transport rates are reflected mainly in different rates of topographical change.

Upon comparison with LNH's measured data, it looks as though 1.5 day of simulation time is somewhat too short to reach the state at which the measurements were taken. Therefore, the DH-model was run for a longer period of time (arbitrarily chosen 5 days), in order to check whether the model re- 
sults would tend towards the observed state. Fig. 7 shows that these $2 \mathrm{DH}$ models reproduce the principal features of the bed evolution in the experiments, in spite of the limitations of non-inclusion of cross-shore profile evolution. Especially noteworthy are the larger coherence of the sedimentation and erosion areas, and the extension of the updrift erosion area into the bay.

\section{Case 2: river outflow}

The river outflow case is meant to test the models for the combined effects of a river outflow and a steady wave-driven longshore current on the sediment transport and the morphological evolution. Though purely hypothetical, this case contains many salient features of real-life applications, such as longshore currents through open side-boundaries and exchange of water and sand through a gap in a closed boundary. Thus, the formulation of openboundary conditions is also tested here.

The initial topography (see Fig. 8a) consists of a plane beach (slope 1:50), which is interrupted by a $75 \mathrm{~m}$ wide river mouth with a water outflow of 150 $\mathrm{m}^{3} / \mathrm{s}$. The bottom contours are straight and parallel to the shoreline, except for a shallow submerged channel in line with the river.

The computational grid is rectangular, with 56 nodes in the $x$-direction (cross-shore) and 111 nodes in the $y$-direction (longshore), with a uniform grid spacing of $15 \mathrm{~m}$.

The waves are irregular and long-crested, with a root-mean-square height of $2 \mathrm{~m}$ at a water depth of $13.5 \mathrm{~m}$. The direction of wave incidence is $30^{\circ}$ with respect to the shore-normal. The peak wave period is $8 \mathrm{~s}$. The bed material is uniform sand of $250 \mu \mathrm{m}$, with a settling velocity of $0.031 \mathrm{~m} / \mathrm{s}$.

The DHI-model uses a constant Manning value of $0.03125 \mathrm{~m}^{1 / 3} / \mathrm{s}$, but this turned out to yield too weak longshore currents in the other models, in which the wave-induced shear stress enhancement is explicitly taken into account, e.g. via Bijker's (1966) waves-plus-current shear stress formula.

Therefore, the friction factor is adjusted in these other models, such that all models produce approximately the same distribution of the longshore current. This is particularly important in order to have the same ratio of coastal and river currents.

This case was run with each of the four models. Fig. 8 shows some of the results. Here the wave and current fields on the initial topography are quite similar for all the models, although there are differences in the degree of flow separation downstream of the river mouth. The sediment transport fields differ mainly in scale (the HR-model gives the highest transport rates now), except for the one from the UL-model, where the transport maximum lies further offshore and the transport from the river is smaller than in the other models.

Fig. 9 shows the morphological changes after 4 days of evolution. All models 


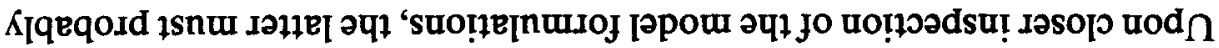

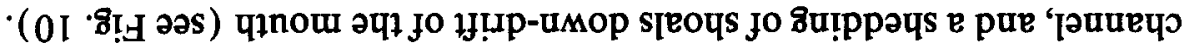

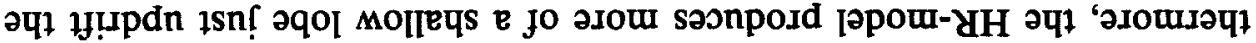

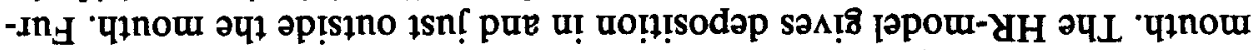

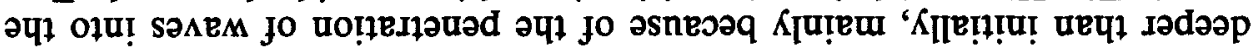

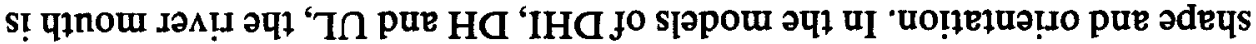

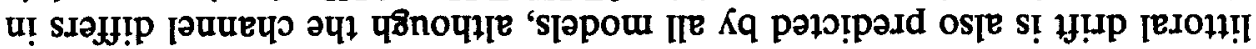

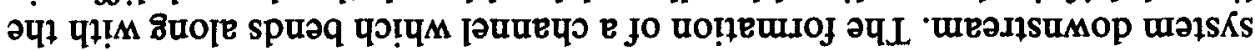

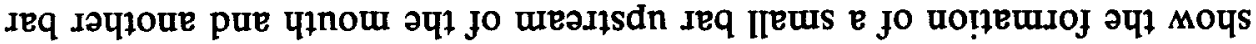

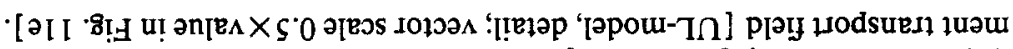

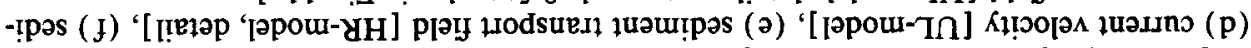

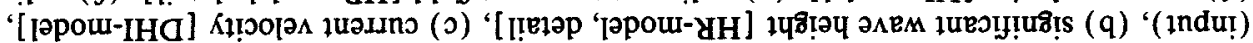

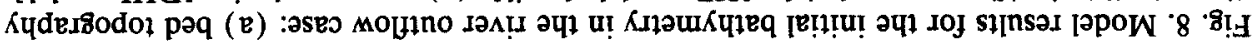

$(1)$

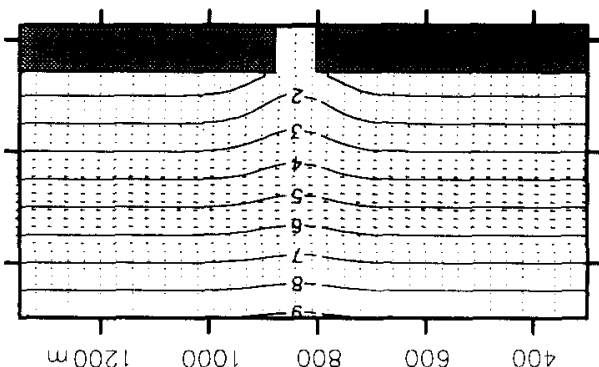

(P)

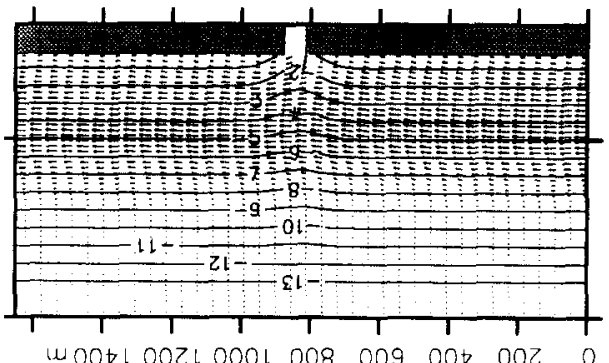

(q)

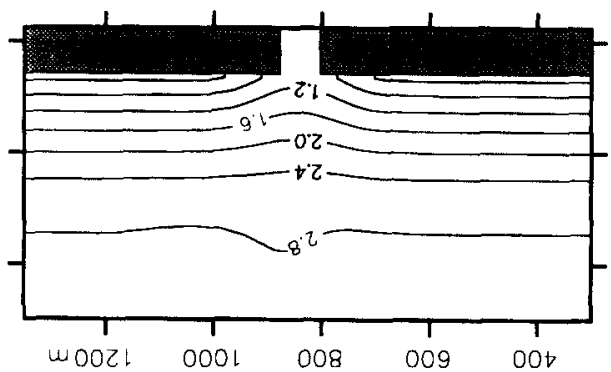

TV I (a)

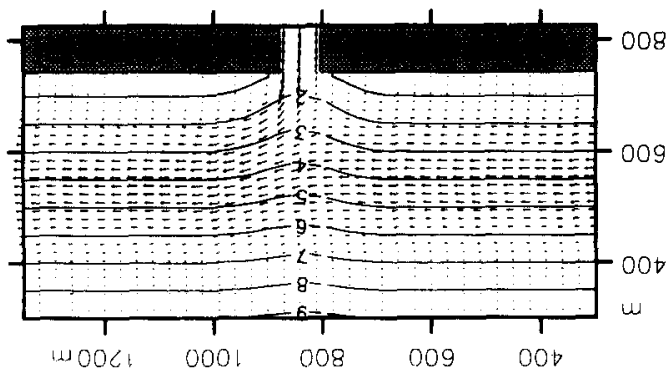

(0)

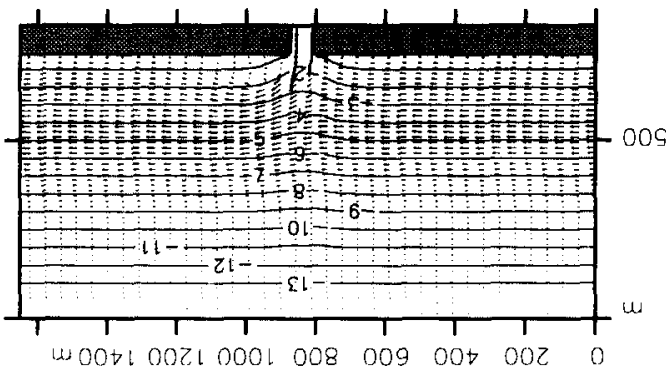

(D)

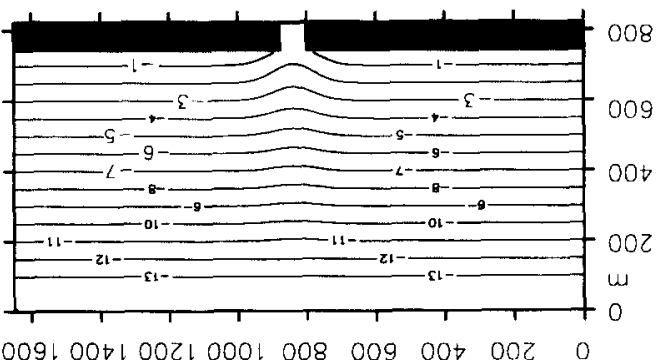



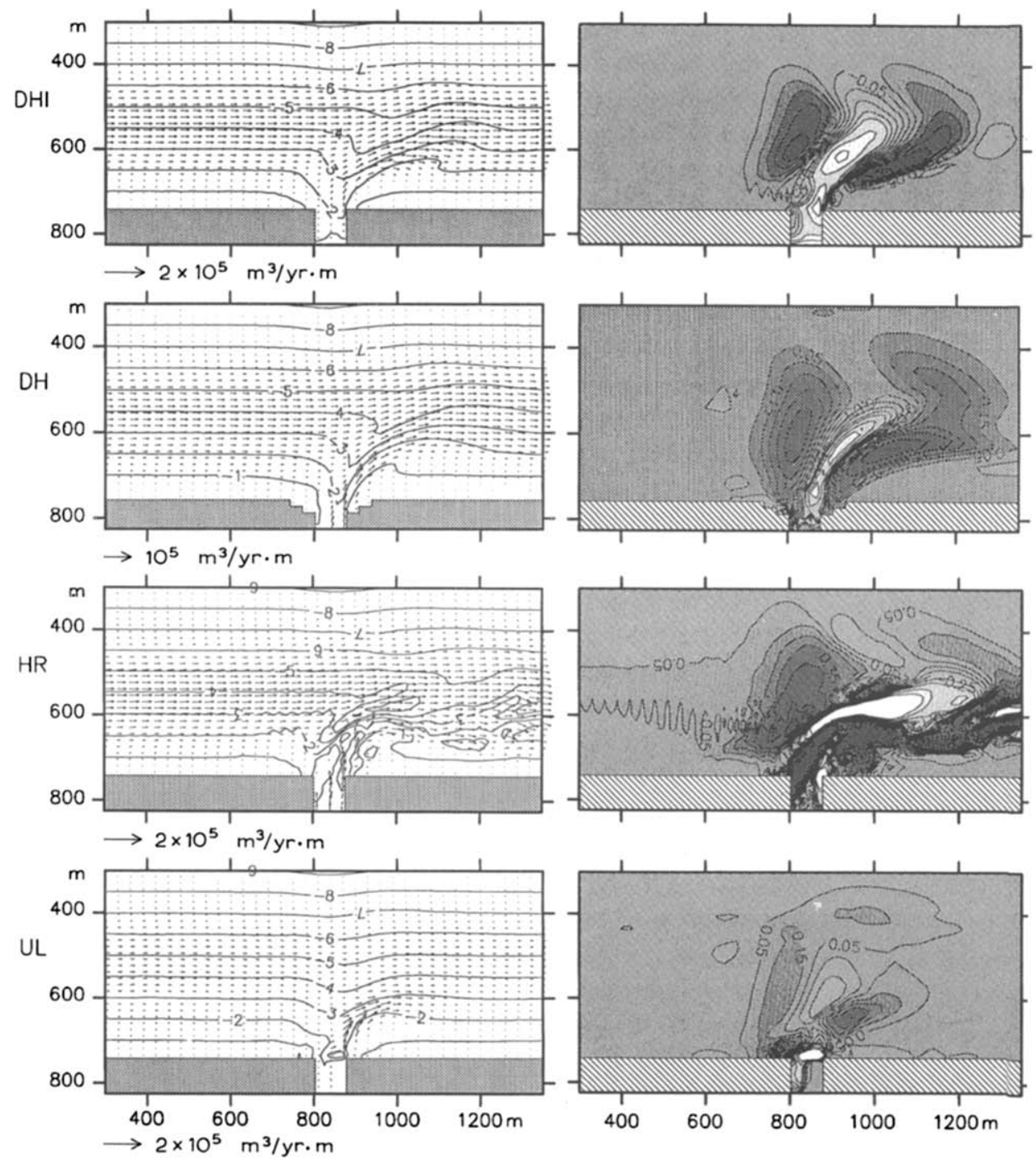

Fig. 9. Model results for the river outflow case after 4 days (UL: $80 \mathrm{hrs}$.) of morphological evolution: sediment transport (left) and cumulative bed level change (right), according to the models of DHI, DH, HR and UL, respectively.

be attributed to the stronger effect of waves in the transport formula, which seems to result in a much more dynamic behaviour at smaller spatial scales. In general, it looks as though the HR-model has covered a larger part of the morphological evolution process. Presumably, the higher overall transport rates lead to smaller morphological time scales than in the other models. This 

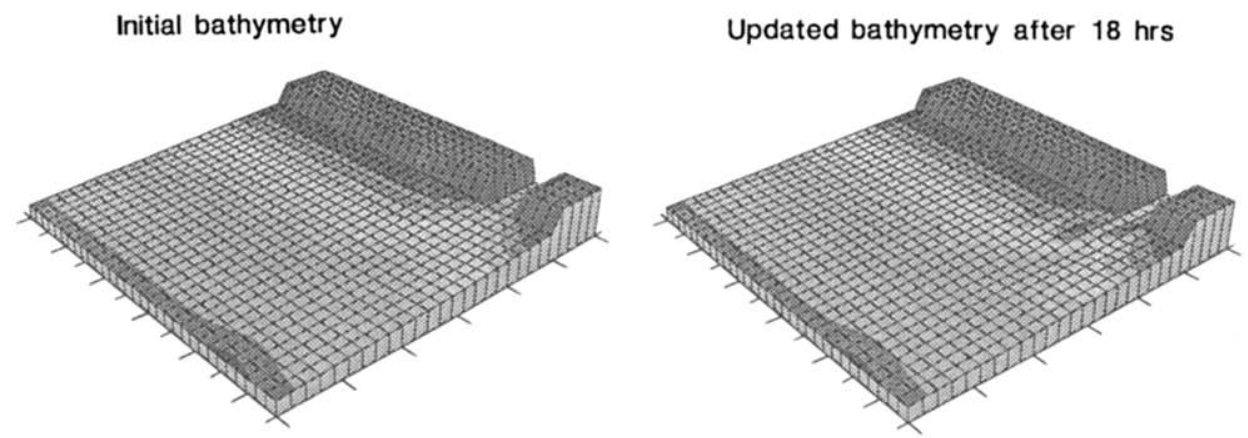

Updated bathymetry after $36 \mathrm{hrs}$

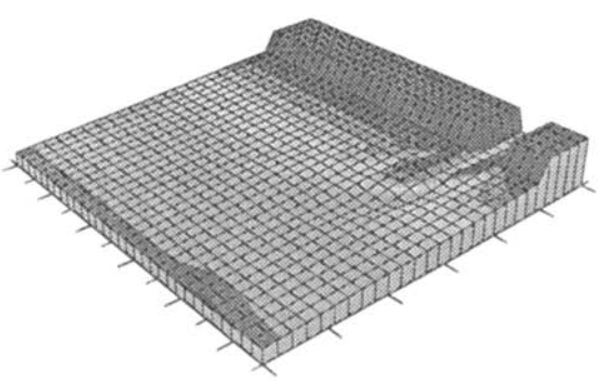

Updated bathymetry after $54 \mathrm{hrs}$

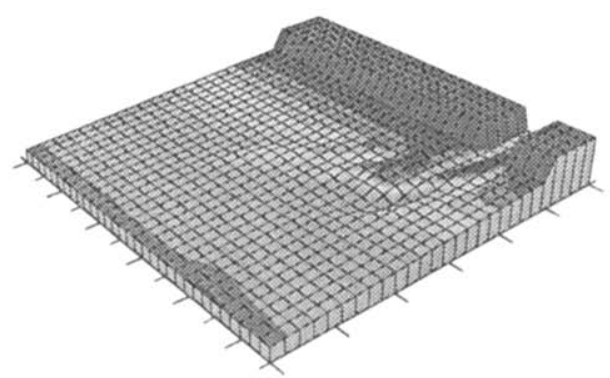

Updated bathymetry after $72 \mathrm{hrs}$

Updated bathymetry after $96 \mathrm{hrs}$
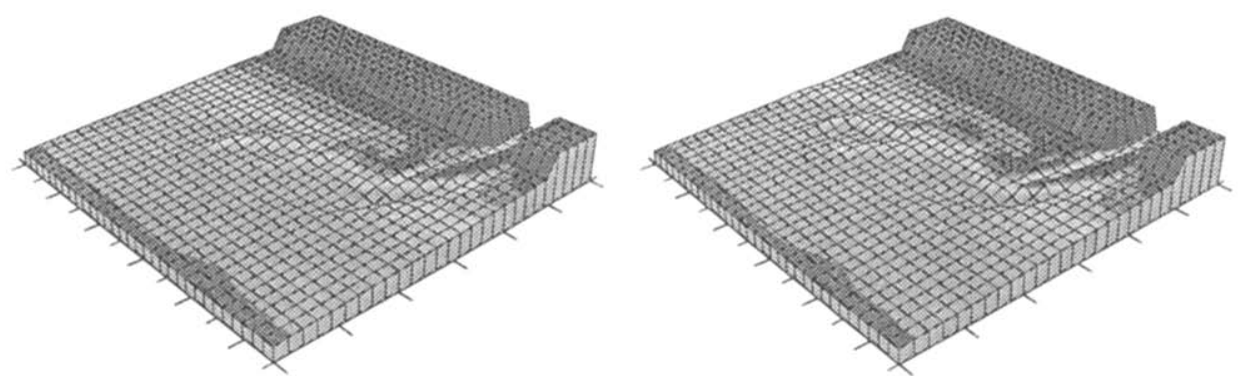

Fig. 10. Bed evolution according to the HR-model. (Note the shedding of a sand bank at 96 hrs.)

stresses the importance of having the order of magnitude of the sediment transport rates right when making model predictions.

Although these results cannot be validated against measured data, they look quite realistic. There is also a good deal of agreement between the models, in spite of the wide variety of especially the transport models.

In order to investigate the equilibrium bed topography, the DH-model was 


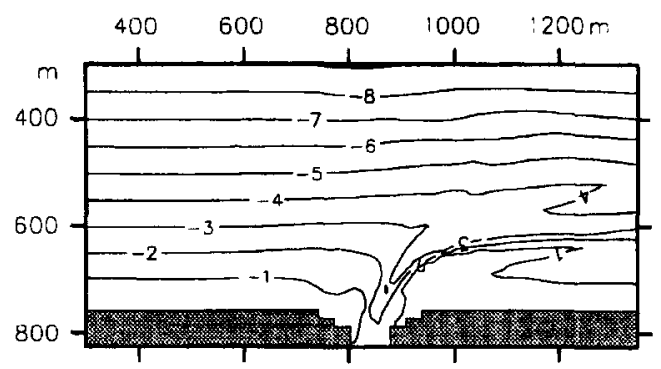

(a)

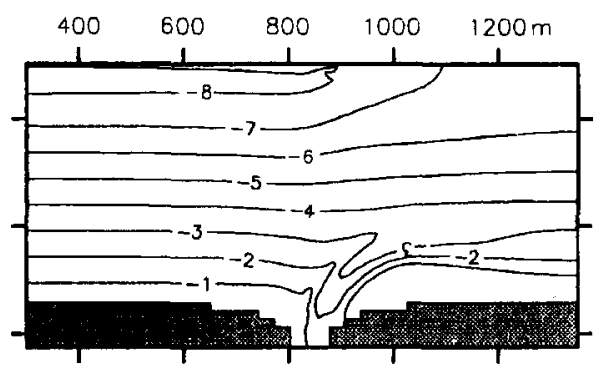

(b)

Fig. 11. River outflow case: equilibrium bed topography: (a) time-evolution model ( $t=18.4$ days), (b) direct computation.

run for a longer time (beyond 18 days), with the same input conditions throughout. After this period, the bed evolution had virtually stopped, and hence the result (Fig. 11a) is assumed to represent the equilibrium state.

In addition, the direct computation method for the equilibrium state on the basis of Eq. (7) was applied to this case (Van Oudenhoven, 1992). This seems to be justified because the differences between the initial and the final transport patterns are very small. Fig. $11 \mathrm{~b}$ shows that the result of this very simple and cheap computation agrees rather well with that of the expensive time-evolution computation.

A direct computation on the basis of the initial hydrodynamic conditions will not always be so successful. If the transport pattern changes during the process, the direct computation has to be iterated together with the hydrodynamic and transport computations. In that case, much of the advantage of the direct computation method is lost.

\section{QUASI-3D MODELS}

As stated before, the 2DH approach has a limited applicability and fails where cross-shore transport mechanisms are important. In order to model these situations, the 3D flow structure has to be described.

One way to achieve this is to include a flow module which solves the hydrodynamic equations on a 3D grid, usually under the assumption of hydrostaticity. In view of the number of calls of the flow module in a morphodynamic computation, this may not always be an attractive option.

In a wide range of practical applications we can make use of the difference in scale of the predominant flow processes in the horizontal plane and in the vertical, and often also between those in the longshore and the cross-shore direction. This opens the way to quasi-3D concepts, such as 
- n-profile models, which consist of a series of more or less parallel crossshore profile models which are coupled via mass balances for water and sediment, or

- 2DH models with IDV postprocessing, and quasi-3D models in which a $2 \mathrm{DH}$ model is coupled to a $1 \mathrm{D}$-vertical model; the latter describes the vertical flow structure and the closure relationships (e.g. the bed shear stress as a function of the depth-averaged velocity) of the $2 \mathrm{DH}$ model. This approach is a rather straightforward extension of the 2DH concept. Most of these concepts are in an early stage of development and have hardly been tested in practice (cf. De Vriend and Ribberink, 1988), but they are probably the best way to proceed in the further development of coastal area morphodynamic modelling.

\section{DISCUSSION}

\section{Physical processes}

The two test cases which have been run so far are by no means sufficient to draw definitive and general conclusions on the importance of the various physical processes.

As intended when defining the present test cases, the wave models give very similar results, because shoaling, refraction and especially breaking of longcrested waves are the most important phenomena here. The cases are therefore not very discriminative for the wave model concepts, which differ on points such as diffraction and directional spreading.

Clearly, wave-current interaction can have significant effects if the geometry and the flow field are sufficiently acute, e.g. with acute angles or pronounced features (also see Ohnaka and Watanabe, 1990). This explains why the effects are less apparent in the present cases.

The results obtained with the four different transport models show the importance of both the overall magnitude of the transport and its response to local variations in hydrodynamic conditions. The former determines the overall time-scale of the morphodynamic process, the latter the small-scale dynamic behaviour.

However, we have to be careful here, since the cases are hypothetical and we have only made overall pattern comparisons between the models, rather than detailed quantitative comparisons. Besides, in order to focus attention on the bottom evolution, we have considered only $2 \mathrm{DH}$ currents so far, whereas the principal difficulties are likely to be met when combining these with "cross-current" transport mechanisms (cf. Roelvink and Brøker Hedegaard, 1993). 


\section{Model structure}

As long as coastal area morphodynamic models are in the present stage of development, flexibility in their composition is of vital importance. This does not only apply to the constituent modules, but also to the way these are linked (the flow chart; see Fig. 12). There are numerous choices to be made there, and many of them are still rather uncertain.

In the hydrodynamic computation (waves and currents), some of these choices concern wave-current interaction (WCI):

- should we always include a WCI-loop in the hydrodynamic computation?

- if yes, should this lead this to a fully converged solution, or can we do with

a small number of iterations?

The present tests have shown that WCI can be locally important, so we have to make provisions for a WCI-loop. Whether we always need a fully converged solution, however, remains to be investigated.

Another aspect of the hydrodynamics is inherently related to the time-stepping procedure: if we choose a simple intermediate updating technique for small bottom perturbations, we have to include updating modules and we have to decide how many times these are called before the full hydrodynamic computation is made again. The only update concept which has been tested so far is the "continuity correction" approach, in which the wave height and the product of current velocity and water depth are kept invariant at every location. More sophisticated techniques for waves and currents are under investigation.

The effects of the number of intermediate updates were tested with the DHmodel in the semi-circular bay case. Increasing the number leads to a substantial reduction of computer costs, at the expense of the smoothness of the morphological evolution with time. As long as the number is kept within reasonable bounds, systematic errors remain small: after every call of the full hydrodynamic model, the bed topography virtually coincides with what is obtained without intermediate up-dates. So far, this very favourable property

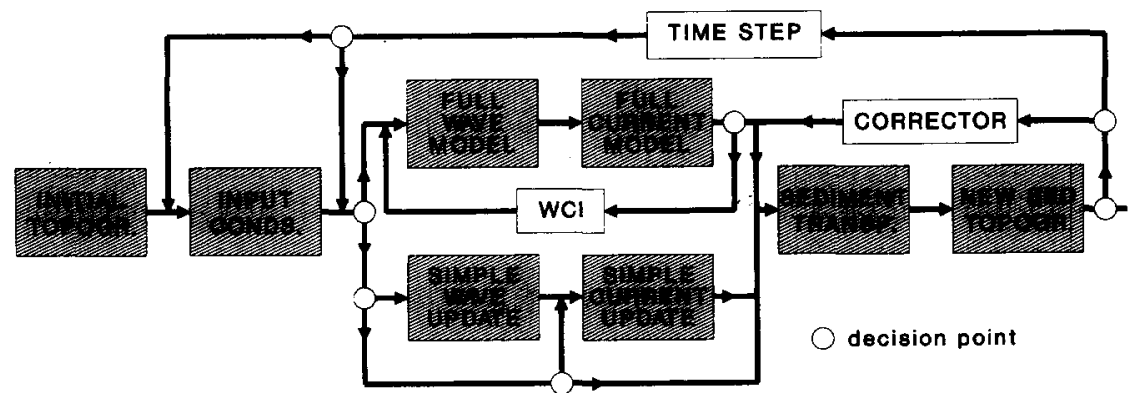

Fig. 12. Flow chart of a coastal area morphodynamic model. 
of the system has been observed in all tests, also in river applications (for instance, see Struiksma et al., 1985).

Apart from the physical choices to be made for the transport module (e.g. bed load or suspended load, total load formula or advection/ diffusion model, intra-wave or wave-averaged), there are a few operational choices to be made. Depending on the time-stepping procedure and the numerical scheme, the transport module is called very often and should therefore be efficient.

If a complex transport model is chosen, such as DHI's intra-wave transport model, it can be useful to tabulate model output beforehand and interpolate between these data during the computation. Another way to reduce the number of calls is to provide not only the transport rate, but also its total derivative with respect to the bed level, so that one can use a linearization of the transport in the bottom evolution module. This is basically what is done in DH's numerical scheme. So far, experience with either approach, each within its own context, is satisfactory.

Coastal area morphodynamic modelling involves a rather heavy informatics component, even if we are only dealing with research versions of the programs. In order to be able to run existing models in a time-loop with reasonable efficiency, such that numerical experiments are practically feasible, the transfer of data between the constituent models and the running of these models have to be very efficient.

\section{Numerical scheme}

However simple the sediment balance equation may seem, its numerical integration poses special problems in morphodynamic models. Through this equation, the constituent modules are linked to the topographic changes. Hence the stability and the accuracy of the whole system depend to a large extent on the numerical scheme for this equation.

Since we want flexibility and a modular system based on existing constituent models, it is impossible to develop a fully implicit numerical scheme, but we may attempt to approximate implicitness via multi-step explicit schemes (for instance, see Vreugdenhil, 1982, and Peltier et al., 1991).

In the present models, we use one-step explicit schemes, with special measures to eliminate numerical diffusion, e.g. via the Lax-Wendroff approach. These schemes have all passed through the rather severe test of a propagating non-linear sand wave (see Peltier et al., 1991).

Nevertheless, there remain many open questions, especially on the accuracy of the schemes and of the computational process as a whole (cf. De Vriend, 1987a ). Further research is needed to clarify these points. 


\section{Time-stepping procedure}

Although the numerical scheme is intrinsically related to the time-stepping procedure, they are not identical; the time-stepping procedure refers to the way the computational process proceeds. As indicated before, time-stepping is an issue because we want to reduce the number of calls of the time-consuming hydrodynamic modules to a minimum. In the present tests, we have used two approaches: a simplified predictor-corrector approach with relatively large time steps between full hydrodynamic recalculations (DHI-model), and a one-step explicit approach with small time steps and simple intermediate updates of the velocity field via the "continuity correction" approach.

Both approaches seem to work well, and we have no indication for either of them to produce systematic errors. The one-step approach is somewhat more transparent, and hence easier to analyse.

The effective morphological time step in the predictor-corrector approach was much smaller than the time-interval between two successive calls of the full hydrodynamic modules in the one-step procedure. It has to be noted, however, that the accuracy requirements imposed on either approach did not match, and hence a quantitative comparison is difficult.

Anyhow, the time-stepping procedure, as well as the numerical scheme, need further investigation before being well-controlled and robust.

\section{Potential applicability}

Although the models in their present form are clearly applicable to certain classes of problems, their applicability is limited by various factors, among which

- physical limitations: the absence of "cross-current" transport mechanisms limits the applicability to cases where the effects of these mechanisms are unimportant or can be included in a parametric way (Watanabe's approach ); examples of such cases are scour in contraction areas (e.g. near the tip of a breakwater), sediment deposits or borrowing pits seaward of the surfzone, shipping channels, sand bank systems outside the beach breakerzone, outer deltas of tidal inlets, etc.;

- input limitations: the models are essentially deterministic, in that they describe the deterministic morphological processes in reponse to deterministic inputs; if we want to use such models for real-life predictions, there are only a few options, viz.:

+ make many runs with different input time-series in order to cover stochastic input variability and chronology; with the present hardware facilities, this will be prohibitively time-consuming;

+ estimate both the "mean" and the "variance" of the predicted evolution from a small number of runs; for the time being, we know too little 
of coastal area morphodynamic processes to claim reasonable accuracy here;

+ make only a few runs and accept that the model gives just an indication of the nature and the scale of morphological behaviour. This should suffice for many studies, the more so because the input conditions are also unpredictable in a deterministic sense.

- economic limitations: the models take quite some computer time and memory, and their operation involves a substantial amount of work in the preparation of inputs and the processing of outputs; hence the system is not yet so versatile, that extensive experimentation programmes can be executed without too many budgetary consequences.

On the other hand, the results so far are sufficiently encouraging to substantiate the application of this type of model to more realistic cases, provided that these allow for a model concept based on a 2DH flow computation.

The incorporation of more of the "cross-current" transport mechanisms will extend the applicability of the models to cases where "longshore" and "cross-shore" interact, including surf zone phenomena such as rip channels, bar systems, pipeline landfalls, sediment bypassing schemes, etc.. To that end, it is necessary to develop further models which describe also the vertical structure of the water and sediment motion, either quasi-3D (making use of similarity assumptions; for instance, see De Vriend and Stive, 1987, SánchezArcilla et al., 1992, and Katopodi and Ribberink, 1992), or even fully 3D.

\section{CONCLUSION}

The foregoing leads to the conclusion, that significant achievements have been made in the numerical modelling of 3D coastal morphology, but that more research over a wide area is needed in order to validate these models and to make them robustly applicable to practical situations.

Initial sedimentation/erosion models definitely deserve their place in coastal morphological modelling, though not as a quantitative predictor of morphological evolution, but rather as a diagnostic tool for process analysis and orientation.

The prediction potential of strictly 2D-horizontal morphodynamic models will probably remain restricted to special classes of problems and short-term evolutions (i.e. the fast response to a big interference with the natural system ), at least in the nearshore zone, since they are lacking the 3D flow structure, which is essential for longer-term evolutions.

The results from the "empirical emulation" of 3D beach processes in Watanabe's model (Watanabe et al., 1986, 1991; Ohnaka and Watanabe, 1990) are encouraging enough to have high expectations of quasi-3D models, which include the vertical structure of the water and sediment motion without making fully $3 \mathrm{D}$ flow computations. 


\section{ACKNOWLEDGEMENT}

This paper is based on work carried out in the "G6 Coastal Morphodynamics" project, in the framework of the EC-sponsored Marine Science and Technology Programme (MAST), under contract No. MAST-0035C. Much of this work was also co-sponsored by various national funding agencies, among which:

- the "Coastal Genesis" programme of the Netherlands Ministry of Transport and Public Works (Rijkswaterstaat),

- the Danish Technical Research Council (STVF),

- the U.K. Ministry of Agriculture, Fisheries and Food, and

- the Service Technique Central des Ports Maritimes et des Voies Navigables (STC, Compiègne, France).

The authors are greatly indebted to their colleagues in this project, especially those involved in "Topic 5B: Coastal Area Models", for their contributions and discussions. They also wish to express their gratitude to those who have worked hard to make these models operational, and to the co-workers and students who have done a significant part of the model running work.

\section{REFERENCES}

Abbott, M.B. and Larsen, J., 1985. Modelling circulations in depth-integrated flows. J. Hydraul. Res., 23: 309-326, 397-420.

Abbott, M.B., McCowan, A.D. and Warren, I.R., 1981. Numerical modelling of free-surface flows that are two-dimensional in plan. In: H.B. Fischer (Editor), Transport Models for Inland and Coastal Waters. Academic Press, New York, pp. 222-283.

Andersen, O.H., Hedegaard, I.B., Deigaard, R., de Girolamo, P. and Madsen, P., 1988. Model for morphological changes under waves and current. In: Proc. IAHR Symp. Math. Mod. Sed. Transp. Coastal Zone, Copenhagen. DHI, Horsholm, pp. 310-319.

Andersen, O.H., Hedegaard, I.B., Ronberg, J.K. and Deigaard, R., and Madsen, P., 1991 . Model for morphological changes in the coastal zone. In: Preprints IAHR Symp. Susp. Sed. Transp., Florence, pp. 327-338.

Bailard, J.A., 1981. An energetics total load model for a plane sloping beach. J. Geophys. Res., 86(C11): 10938-19854.

Bijker, E.W., 1966. The increase of bed shear in a current due to wave action. In: Proc. 10th ICCE, Tokyo, pp. 746-765.

Chaloin, B., Péchon, Ph. and Coëffe, Y., 1985. Hydraulic studies of the bed evolution of the River Canche estuary and of the Dunkirk harbour extensions. In: J.H. Pounsford (Editor), Proc. Int. Conf. Num. and Hydr. Mod. of Ports and Harbours, Birmingham. BHRA, Bedford, pp. 51-64.

Chesher, T.J. and Miles, G.V., 1992. The concept of a single representative wave for use in numerical models of long-term sediment transport predictions. In: R.A. Falconer, S.N. Chandler-Wilde and S.Q. Liu (Editors), Proc. 2nd Int. Conf. on Hydr. and Env. Mod. of Coastal, Est. and River Waters, Bradford. Ashgate, Brookfield, VT, pp. 371-380.

Coëffé, Y. and Péchon, $\mathrm{Ph} ., 1982$. Modelling sea bed evolution under waves action. In: Proc. 18th ICCE, Cape Town, pp. 1149-1160. 
Dean, R.G., 1977. Equilibrium beach profiles: US Atlantic and Gulf Coasts. Univ. Delaware, Dept. Civil Eng., Ocean Eng. Rept. 12, 45 pp.

Deigaard, R., Fredsøe, J. and Hedegaard, I.B., 1986a. Suspended sediment in the surf zone. J. Waterw. Port, Coastal Ocean Eng., 112(1): 115-128.

Deigaard, R., Fredsøe, J. and Hedegaard, I.B., 1986b. Mathematical model for littoral drift. J. Waterw. Port, Coastal Ocean Eng., 112(3): 351-369.

De Vriend, H.J., 1986. 2DH computation of transient sea bed evolutions. In: Proc. 20th ICCE, Taipei, pp. 1689-1712.

De Vriend, H.J., 1987a. 2DH mathematical modelling of morphological evolutions in shallow water. Coastal Eng., 11(1): 1-27.

De Vriend, H.J., 1987b. Analysis of 2DH morphological evolutions in shallow water. J. Geophys. Res., 92(C4): 3877-3893.

De Vriend, H.J., 1988. Inherent stability of depth-integrated models of coastal morphology. In: Proc. IAHR Symp. Math. Mod. Sed. Transp. Coastal Zone, Copenhagen, pp. 320-329.

De Vriend, H.J., 1991a. G6 Coastal Morphodynamics. In: N.C. Kraus, K.J. Gingerich and D.L. Kriebel (Editors), Proc. Coastal Sediments '91, Seattle, WA. ASCE, New York, pp. 356370.

De Vriend, H.J., 1991b. Modelling in marine morphodynamics. In: A. S.-Arcilla, M. Pastor, O.L. Zienkiewicz and B.A. Schrefler (Editors), Proc. CMOE'91 Conf., Barcelona. Balkema, Rotterdam, pp. 247-260.

De Vriend, H.J. and Ribberink, J.S., 1988. A quasi-3D mathematical model of coastal morphology. In: Proc. 21st ICCE, Malaga, pp. 1689-1703.

De Vriend, H.J. and Stive, M.J.F., 1987. Quasi-3D modelling of nearshore currents. Coastal Eng., 11(5/6): 565-601.

Dingemans, M.W., Radder, A.C. and De Vriend, H.J., 1987. Computation of the driving forces of wave-induced currents. Coastal Eng., 11(5/6): 539-563.

Fritsch, D., Teisson, Ch. and Manoha, B., 1989. Long term simulation of suspended sediment transport: Application to the Loire estuary. In: Proc. 23rd IAHR-Congress, Ottawa, Ont. NRC, Ottawa, Ont., pp. C.277-C.284.

Gallerano, P. and Rufini, P., 1989. Sediment erosion and deposition around agroin perpendicular to coastline. In: Proc. 23rd IAHR Congress, Ottawa, Ont. NRC, Ottawa, Ont., pp. C.177C. 184.

Holthuijsen, L.H., Booij, N. and Herbers, T.H.C., 1989. A prediction model for stationary, shortcrested waves in shallow waters with ambient currents. Coastal Eng., 13: 23-54.

Horikawa, K., 1988. Nearshore Dynamics and Coastal Processes. University of Tokyo Press, Tokyo, 522 pp.

Howd, P.A. and Birkemeier, W.A., 1987. Storm-induced morphology changes during DUCK85. In: N.C. Kraus (Editor), Proc. ASCE Conf. Coastal Sediments '87, New Orleans, LA. ASCE, New York, pp. 834-847.

Huthnance, J.M., 1982. On one mechanism forming linear sand banks. Estuarine Coastal Shelf Sci., 4: 79-99.

Katopodi, I. and Ribberink, J.S., 1992. Quasi-3D modelling of suspended sediment transport by currents and waves. Coastal Eng., 18: 83-110 (err. 19: 339).

Latteux, B., 1980. Harbour design including sedimentological problems using mainly numerical techniques. In: Proc. 17th ICCE, Sydney, pp. 2213-2229.

Maruyama, K. and Takagi, T., 1988. A simulation system of near-shore sediment transport for the coupling of the sea-bottom topography, waves and currents. In: Proc. IAHR Symp. Math. Mod. Sed. Transp. Coastal Zone, Copenhagen, pp. 300-309.

Miles, G.V. and Cooper, A.J., 1985. Application of a DAP computer to tidal problems. In: Proc. Int. Conf. Num. and Hydr. Mod. of Ports and Harbours, Birmingham.

O'Connor, B.A. and Nicholson, J., 1992. An estuarine and coastal sediment transport model. In: D. Prandle (Editor), Dynamics and Exchanges in Estuaries and the Coastal Zone. Springer Verlag, New York. 
Ohnaka, S. and Watanabe, A., 1990. Modelling of wave-current interaction and beach change. In: Proc. 22nd ICCE, Delft, pp. 2443-2456.

Pattiaratchi, C. and Collins, M., 1987. Mechanisms for linear sandbank formation and maintenance in relation to dynamical oceanographical observations. Prog. Oceanogr., 19: 117176.

Péchon, Ph., 1985. Experimental study of the littoral transport and first comparisons with the model TRADEF. EDF-LNH, Report HE 42/85.05 (in French).

Péchon, Ph., 1988. Comparison of a numerical model for longshore sediment transport with measurements. In: B.A. Schrefler and O.G. Zienkiewicz (Editors), Computer Modelling in Ocean Engineering. Balkema, Rotterdam, pp. 451-460.

Peltier, E., Duplex, J., Latteux, B., Péchon, Ph. and Chausson, P., 1991. Finite element model for bed-load transport and morphological evolution. In: A. S.-Arcilla, M. Pastor, O.C. Zienkiewicz and B.A. Schrefler (Editors), Proc. CMOE ' 91 Conf., Barcelona. Balkema, Rotterdam, pp. 227-233.

Roelvink, J.A. and Brøker Hedegaard, I., 1993. Cross-shore profile models. In: H.J. de Vriend (Editor), Coastal Morphodynamics: Processes and Modelling. Coastal Eng., 21: 163-191.

Rouse, H., 1965. Advanced Mechanics of Fluids. Wiley, New York, 444 pp.

Sánchez-Arcilla, A., Collado, F. and Rodriguez, A., 1992. Vertically varying velocity field in Q3D nearshore circulation. In: Proc. ICCE'92, Venice, pp. 2811-2824.

Shimizu, T., Nodani, H. and Kondo, K., 1990. Practical application of the three-dimensional beach evolution model. In: Proc. 22nd ICCE, Delft, pp. 2481-2494.

Southgate, H.N. and Goldberg, D.G., 1989. An efficient computational model for wave refraction and diffraction using finite differences. HR Wallingford, Report SR213.

Steijn, R.C. and Louters, T., 1992. Hydro- and morphodynamics of a mesotidal inlet in the Dutch Wadden Sea. In: Oceanology Intern.'92 Conf., Brighton.

Steijn, R.C., Louters, T., Van der Spek, A.J.F. and De Vriend, H.J., 1989. Numerical model hindcast of the ebb tidal delta evolution in front of the Delta-works. In: R.A. Falconer, P. Goodwin and R.G.S. Matthew (Editors), Hydraulic and Environmental Modelling of Coastal, Estuarine and River Waters. Gower Technical, Aldershot, pp. 145-156.

Stelling, G.S. and Leendertse, J.J., 1992. Approximation of convection processes by cyclic ADImethods. In: M.L. Spaulding et al. (Editors), Proc. Est. and Coastal Modelling, Tampa, FL. ASCE, New York, pp. 771-782.

Stive, M.J.F., 1986. A model for cross-shore sediment transport. In: Proc. 20th ICCE, Taipei, pp. $1550-1564$.

Struiksma, N., Olesen, K.W., Flokstra, C. and De Vriend, H.J., 1985. Bed deformation in curved alluvial channels. J. Hydraul. Res., 23(1): 57-79.

Van Oudenhoven, T.M.M., 1992. 2DH morphological computations in the vicinity of a river mouth. Delft Hydraulics, MAST-G6M Report H824.52, 70 pp.

Villaret, C. and Latteux. B, 1992. Long-term simulation of cohesive sediment bed erosion and deposition by tidal currents. In: Int. Conf. on Comp. Modelling of Seas and Coastal Regions, Southampton.

Vreugdenhil, C.B., 1982. Finite-difference schemes for bottom change computations in which the celerity needs not to be known. Delft Hydraulics Laboratory, Informatie X 61 (S342), $14 \mathrm{pp}$ (in Dutch).

Walker, D.J., Dong, P. and Anastasiou, K., 1991. Sediment transport near groynes in the nearshore zone. J. Coastal Res., 7(4): 1003-1010.

Watanabe, A., Maruyama, K., Shimizu, T. and Sakakiyama, T., 1986. Numerical prediction model of three-dimensional beach deformation around a structure. Coastal Eng. Jpn., 29: 179-194.

Watanabe, A., Shimizu, T. and Kondo, K., 1991. Field application of a numerical model of beach topography change. In: N.C. Kraus, K.J. Gingerich and D.L. Kriebel (Editors), Proc. Coastal Sediments '91 Conf., Seattle, WA. ASCE, New York, pp. 1814-1828. 
Wright, L.D. and Thom, B.G., 1977. Coastal depositional landforms: a morphodynamic approach. Prog. Phys. Geogr., 1: 412-459.

Yamaguchi, M. and Nishioka, Y., 1984. Numerical simulation on the changes of bottom topography by the presence of coastal structures. In: Proc. 19th ICCE, Houston, TX, pp. 17321748.

Yoo, D. and O'Connor, B.A., 1986. Mathematical modelling of wave-induced nearshore circulations. In: Proc. 20th ICCE, Taipei, pp. 1667-1681. 